\title{
Resolution of exudative retinal detachment and regression of retinal macrocyst post-laser in Coats disease
}

This article was published in the following Dove Press journal:

International Medical Case Reports Journal

7 August 2013

Number of times this article has been viewed

Yusoff Munira'

Embong Zunaina ${ }^{1,2}$

Yaakub Azhany ${ }^{1,2}$

'Department of Ophthalmology, School of Medical Sciences, Health Campus, Universiti Sains Malaysia, Kubang Kerian, Kelantan, Malaysia; ${ }^{2}$ Hospital Universiti Sains Malaysia, Jalan Raja Perempuan Zainab II, Kubang Kerian, Kelantan, Malaysia

Correspondence: Embong Zunaina Department of Ophthalmology, School of Medical Sciences, Universiti Sains Malaysia, 16150 Kubang Kerian, Kelantan, Malaysia

Tel +609767 6362

Fax +6097673370

Email zunaina@kb.usm.my
Abstract: A 15-year-old boy presented with painless progressive blurring of vision in the right eye for 1 year in duration. His visual acuity in the right eye was hand movement. The right fundus showed presence of extensive subretinal exudates at the posterior pole and a retinal macrocyst at the temporal periphery. It was associated with exudative retinal detachment at the inferior periphery of the retina. Fundus angiography revealed telangiectatic retinal vessels at the superotemporal retina. Based on clinical and angiographic findings, a diagnosis of Coats disease was made. He was treated with retinal laser photocoagulation. There was resolution of the exudative retinal detachment, reduction of subretinal exudates, and regression of the retinal macrocyst with improvement of visual acuity to $1 / 60$ post-laser therapy.

Keywords: exudative retinal detachment, retinal macrocyst, Coats disease, laser

\section{Introduction}

Coats disease is a rare idiopathic retinal vascular disease characterized by abnormal telangiectatic vessels with progressive deposition of intraretinal or subretinal exudates. It usually affects boys in their first to second decade of life and less commonly presents in adulthood. ${ }^{1}$ It is unilateral in $90 \%$ of cases. Coats disease normally progresses slowly and results in a gradual loss of vision. ${ }^{2}$

Coats disease is classified into stage 1 (telangiectasia only), stage 2 (telangiectasia and exudation; 2A, extrafoveal exudation; 2B, foveal exudation), stage 3 (exudative retinal detachment; $3 \mathrm{~A}$, subtotal; $3 \mathrm{~B}$, total), stage 4 (total retinal detachment and secondary glaucoma), and stage 5 (advanced end-stage disease). ${ }^{3}$ Treatment is aimed at obliterating the abnormal vessels by either laser photocoagulation ${ }^{2,3}$ or cryotherapy, ${ }^{3}$ while vitrectomy ${ }^{3,4}$ is generally indicated when retinal detachment occurs.

\section{Case report}

A 15-year-old boy presented with painless progressive blurring of vision in the right eye for one year in duration. It was not associated with floaters or flashes of light and there was no history of trauma. He was born full term via spontaneous vaginal delivery and had no past ocular history or medical illness.

Visual acuity in his right eye was hand movement and his left visual acuity was 6/6. Anterior segment examination was normal with a normal pupillary reaction in both eyes. The right fundus showed the presence of extensive subretinal exudates at the posterior pole (macular area) extending to the superotemporal arcade (Figure 1). There was also the presence of a retinal macrocyst at the temporal periphery of the retina (Figure 2A). This was associated with exudative retinal detachment at the 


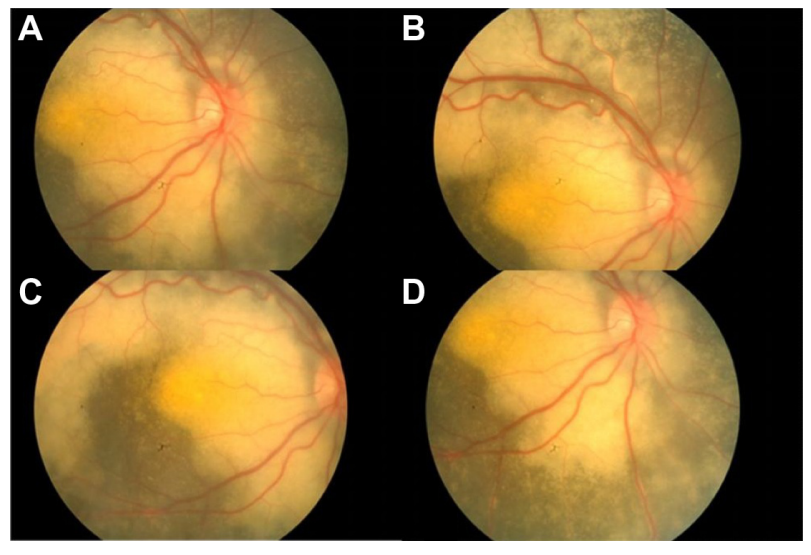

Figure I Fundus findings at presentation show extensive subretinal exudates at posterior pole (C) and superotemporal arcade (D). (A) Surrounding the optic disc, (B) inferior arcade.

inferior periphery of the retina with no foveal involvement. There was the presence of telangiectatic retinal vessels at the superotemporal retina. The left fundus was normal with an absence of subretinal exudates or any abnormal retinal vessels. B-scan ultrasound showed the presence of inferior retinal detachment with no mass lesion or calcification. Fundus angiography revealed telangiectatic retinal vessels at the superotemporal retina.

Based on clinical and angiographic findings, a diagnosis of Coats disease in the right eye was made. The patient was classified as having Coats disease stage $3 \mathrm{~A}$ based on the presence of exudative retinal detachment with no foveal involvement. He was treated with retinal laser photocoagulation at the area of telangiectatic vessels aiming to cause regression of these vessels. The laser therapy was given in four sessions within 3 months.

At 3-month follow-up after initial presentation, the exudative retinal detachment was resolved with minimal reduction of subretinal exudates. Review at 14 months post-retinal laser photocoagulation showed a reduction of the subretinal exudates at the posterior pole (Figure 3 ). There was regression of the size of the retinal macrocyst with reduction of subretinal exudates surrounding the retinal macrocyst at

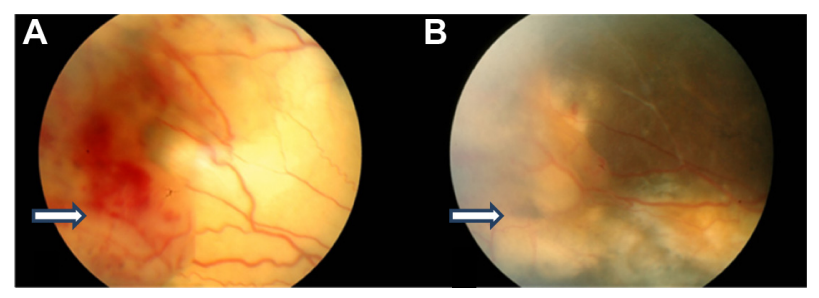

Figure 2 Fundus finding shows retinal macrocyst at temporal periphery of retina (arrow) at presentation (A) and regression of the retinal macrocyst (arrow) at 2 years post-retinal laser photocoagulation (B).

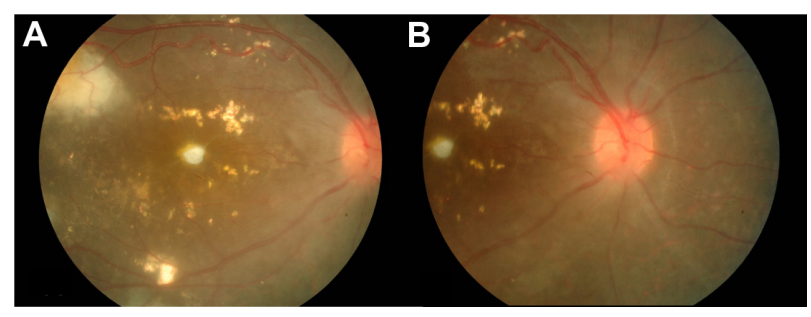

Figure 3 Fundus finding at 14 months post-retinal laser photocoagulation at posterior pole (A) and optic disc (B).

2 years post-retinal laser photocoagulation (Figure 2B). His right visual acuity was improved to $1 / 60$, with no further improvement due to persistent dense and calcified subretinal exudates at the fovea.

\section{Discussion}

The hallmark lesion of Coats disease is retinal telangiectasia and subretinal exudates, as seen in this case. The pathologic process that causes the exudation is increased permeability of telangiectatic vessels, causing leakage of lipoprotein into the retina and subsequently retinal edema., Expression of vascular endothelial growth factor is observed in macrophages infiltrating the subretinal space. Immunoreactivity for vascular endothelial growth factor receptor-2 was detected in endothelial cells lining the abnormal retinal vessels. ${ }^{7}$ The exudation seen is not associated with any sign of vitreoretinal traction. Exudates may also disrupt the underlying retina causing exudative retinal detachment. ${ }^{5}$ Other complications of Coats disease include intraretinal macrocyst. ${ }^{8}$ Retinal macrocyst appears to correlate with the presence of retinal detachment. $^{3,8}$

Telangiectatic vessels found in Coats disease are localized to a focal area on the retina. These telangiectasias may also involve a large area of the retina. Macular exudation may be caused by macular telangiectasia, peripheral retinal telangiectasia, or both. ${ }^{9}$ Exudates that involve the macular area definitely cause poor vision, ${ }^{10}$ and if longstanding, may result in macular scarring, cystoid macular edema, or subfoveal fibrosis. ${ }^{3}$

Treatment by laser photocoagulation is aimed at obliterating the abnormal telangiectatic blood vessels. Cryotherapy is indicated if the abnormal vessels are in the periphery or a large area of exudation is present beneath the telangiectatic vessels. ${ }^{11}$ Treatment of peripheral telangiectatic vessels resulted in resolution of the exudation both in the retinal periphery and at the macula. Intravitreal bevacizumab plus thermal ablation showed resolution of disease in most severe cases. ${ }^{12}$ Complications of abnormal retinal vessels 
such as vitreous hemorrhage or subhyaloid hemorrhage may necessitate vitrectomy to clear the bleeding. Enucleation is indicated in cases with total retinal detachment associated with glaucoma in order to relieve severe ocular pain. ${ }^{3}$ In this case report, the patient was treated with retinal laser photocoagulation which resulted in resolution of exudative retinal detachment, reduction of subretinal exudates, and regression of retinal macrocyst. However, the visual prognosis is poor due to dense and calcified foveal exudation.

\section{Conclusion}

Even though the outcomes are not so promising, treatment, especially for the localized form of Coats disease, is highly recommended because the prognosis without treatment is almost invariably poor.

\section{Disclosure}

The authors report no conflicts of interest in this work.

\section{References}

1. Otani T, Yasuda K, Aizawa N, Sakai F, Nakazawa T, Shimura M. Over 10 years follow-up of Coats' disease in adulthood. Clin Ophthalmol. 2011;5:1729-1732.

2. Feng Y, Ma Z. Transscleral diode photocoagulation of large retinal and choroid vascular lesion. PLoS One. 2012;7:e39340.
3. Shields JA, Shields CL, Honavar SG, Demirci H, Cater J. Classification and management of Coats' disease: the 2000 Proctor Lecture. Am J Ophthalmol. 2001;131:572-583.

4. Nakashima H, Emi K, Sato T, Iwahashi-Shima C, Bando H, Ikeda T. [Long-term prognosis of 5 cases with stage 3A Coats disease after vitrectomy.] Nihon Ganka Gakkai Zasshi. 2012;116:560-567. Japanese.

5. Tarkkanen A, Laatikainen L. Coats' disease: clinical, angiographic, histopathological findings and clinical management. B J Ophthalmol. 1983;67:766-776.

6. Kaul S, Uparkar M, Mody K, Walinjkar J, Kothari M, Natarajan S. Intravitreal anti-vascular endothelial growth factor agents as an adjunct in the management of Coats' disease in children. Indian J Ophthalmol. 2010;58:76-78.

7. Kase S, Rao NA, Yoshikawa H, et al. Expression of vascular endothelial growth factor in eyes with Coats' disease. Invest Ophthalmol Vis Sci. 2013;54:57-62.

8. Shields JA, Shields CL, Honavar SG, Demirci H. Clinical variations and complications of Coats disease in 150 cases: the 2000 Sanford Gifford Memorial Lecture. Am J Ophthalmol. 2001;131:561-571.

9. Rishi P, Ekta R, Uparkar M, et al. Coats' disease: an Indian perspective. Indian J Ophthalmol. 2010;58:119-124.

10. Mahmoud AO, Kolawole O, Ibrahim T, Olokoba L. Coats disease in a Nigerian man with a favorable structural outcome following retinal laser photocoagulation. Ann Afr Med. 2013;12:61-62.

11. Entezari M, Ramezani A, Safavizadeh L, Bassimia N. Resolution of macular edema in Coats' disease with intravitreal bevacizumab. Indian J Ophthalmol. 2010;58:80-82.

12. Ray R, Barañano DE, Hubbard GB. Treatment of Coats' disease with intravitreal bevacizumab. Br J Ophthalmol. 2013;97:272-277.
International Medical Case Reports Journal

\section{Publish your work in this journal}

The International Medical Case Reports Journal is an international, peer-reviewed open-access journal publishing original case reports from all medical specialties. Previously unpublished medical posters are also accepted relating to any area of clinical or preclinical science. Submissions should not normally exceed 2,000 words or

\section{Dovepress}

4 published pages including figures, diagrams and references. The manuscript management system is completely online and includes a very quick and fair peer-review system, which is all easy to use. Visit http://www.dovepress.com/testimonials.php to read real quotes from published authors. 